\title{
Em busca do centro democrático-progressista: o liberalismo agonístico de Max Weber
}

\author{
CARLOS EDUARDO SELL ${ }^{I}$
}

"É preciso entregar-se ao trabalho e responder às exigências do dia".

$\mathrm{H}$ Á UM EPISÓDIO da vida de Max Weber que revela muito sobre sua visão e sua prática da política. Em 28 de novembro de 1918, depois da abdicação da monarquia, ele ingressou na comissão organizadora do recém-fundado Partido Democrático Alemão (DDP), candidatando-se pelo círculo eleitoral de Hessen-Nassau (região de Frankfurt) como futuro representante para a Assembleia Nacional Constituinte.

Na época, o sistema partidário da Alemanha era constituído por quatro grandes milieux político-sociais (Lepsius, 1993, p.25-50). O primeiro era formado pelos conservadores que, com sua base agrária e tradicionalista, eram representados por partidos fragmentados nas esferas regionais, divisão que só foi relativamente superada em 1912, com a fundação do Partido Nacional Popular da Alemanha (Deutschnationale Volkspartei). Os grupos liberais tinham sua base social nas camadas burguesas e no protestantismo de corte progressista. Inicialmente representados no Partido do Progresso Alemão (Deutsche Fortschrittspartei), de 1861, eles ramificaram-se em dois segmentos, com a ala mais à esquerda reunida em torno do Partido Popular Alemão (Deutsche Volkspartei) e os grupos mais à direita organizados no Partido Nacional-Liberal (Nationalliberale Partei), de 1867. No centro do sistema partidário estava uma agremiação ligada à Igreja católica, o chamado Partido Católico de Centro (Zentrumspartei), que foi fundado em 1870 como resultado do conflito entre forças religiosas e laicas conhecido como Kulturkampf (Luta cultural). Na esquerda do espectro político estava o Partido Social-Democrata (SPD) que, oficialmente, surgiu em 1875, em Gotha, a partir da fusão dos grupos de August Bebel (fundado em 1869) e de Ferdinand Lassalle (fundado em 1863). Em 1891 ele adotou o programa revisionista de Karl Kautsky e Eduard Bernstein. Mais à frente, com a eclosão da Revolução russa, as forças da esquerda vão dividir-se, surgindo daí o 
Partido Social-democrata Independente da Alemanha (UPSD - Unabhängige Sozialdemokratische Partei Deutschlands), de curta duração, e o Partido Comunista Alemão (KPD), liderado por Karl Liebknecht e Rosa Luxemburg, em 1918.

Esse sistema partidário foi bastante estável e, como demonstrou Rainer Lepsius (1993), manteve-se operando até meados da República de Weimar (que se inicia em 1919), quando o surgimento de partidos de extrema-direita começou a abalar o quadro político, o que a Tabela 1 , dividida em duas partes, quer justamente indicar.

Tabela 1 - Evolução do sistema partidário alemão (1871-1928)

\begin{tabular}{l|l|l|l|l|l}
\hline ANO & Conservadores & Liberais & Centro & Esquerda & Demais \\
\hline 1871 & 23 & 40 & 19 & 03 & 15 \\
\hline 1874 & 14 & 39 & 28 & 07 & 12 \\
\hline 1877 & 18 & 38 & 25 & 09 & 10 \\
\hline 1878 & 27 & 33 & 23 & 08 & 09 \\
\hline 1881 & 24 & 37 & 23 & 06 & 09 \\
\hline 1884 & 22 & 37 & 23 & 10 & 08 \\
\hline 1887 & 25 & 36 & 20 & 10 & 09 \\
\hline 1890 & 19 & 34 & 19 & 20 & 08 \\
\hline 1893 & 19 & 27 & 19 & 23 & 12 \\
\hline 1898 & 16 & 24 & 19 & 27 & 14 \\
\hline 1903 & 14 & 23 & 20 & 32 & 12 \\
\hline 1907 & 14 & 25 & 19 & 29 & 13 \\
\hline 1912 & 12 & 26 & 16 & 35 & 11 \\
\hline Ano & DNVP & DVP e DDP & ZENTRUM & SPD e KPD & $\begin{array}{l}\text { NSDAP } \\
\text { e BVP demais }\end{array}$ \\
\hline 1919 & 10 & 23 & 20 & 45 & 05 \\
\hline 1920 & 15 & 15 & 18 & 42 & 03 \\
\hline 1924 & 20 & 16 & 17 & 33 & 14 \\
\hline 1924 & 21 & 14 & 35 & 40 & 11 \\
\hline 1928 & & 15 & 17 & 17 \\
\hline
\end{tabular}

Fonte: Lepsius (1993, p.33). As siglas correspondentes são: DNVP: Partido Nacional Popular Alemão; DVP: Partido Popular Alemão; DDP: Partido Democrático Alemão; BVP: Partido Bávaro Alemão; SPD: Partido Social Democrata da Alemanha; KPD: Partido Comunista da Alemanha; NSDAP: Partido Nacional Socialista dos Trabalhadores Alemães. 
Weber, que permaneceu ligado às forças liberais (DDP), lutou bravamente na cena partidária. Existem documentos que resgatam suas falas ao longo de diversas intervenções feitas em 1918-1919, em Frankfurt (1 de dezembro), Wiesbadenm ( 5 de dezembro), Berlim (20 de dezembro), Heidelberg ( 2 e 7 de janeiro), Karlsruhe ( 4 de janeiro) e Fürth (14 de janeiro). Sabe-se ainda que ele deveria estar presente em Hanau (9 de dezembro), Frankfurt, Karlsruhe, Sinsheim (entre 12 e 15 de janeiro) e Thüringen ( 18 de janeiro), mas esses últimos eventos acabaram não se realizando (Weber, MWG I/16, p.157). O motivo é que após uma intensa luta no interior da burocracia partidária, Weber foi posto em lugar completamente secundário na lista de candidatos. Apesar da tentativa de inscrever-se em outra circunscrição eleitoral (Karlsruhe), a iniciativa fracassou e ele acabou desistindo da candidatura. Sua decepção a respeito desse triste episódio está documentada na dura carta que ele endereçou ao diretório do partido. Apesar do "caráter desagradável" de todo episódio, "por não ser um político profissional, a questão não me é pessoalmente importante". Quanto a sugestão de mudar de circunscrição eleitoral, "por razões democráticas, recuso-me a fazer concessões aos honoráveis do partido" (MWG I/16, p.156).

Qual a lição que podemos extrair desse episódio?

\section{Um intelectual nem um pouco resignado: críticas das interpretações vigentes no Brasil}

As investidas de Weber na carreira política já nos indicam que ele está longe de ser um crítico "resignado" (Cohn, 2003) como se estivesse a observar passivamente uma realidade entregue a um destino inelutável. Partindo dessa premissa teríamos que aceitar também que Weber via a realidade sendo movida somente pela roda da fortuna, faltando-lhe o elemento da virtú. Logo Weber, o teórico por excelência da ação?

Que Weber era um "crítico" da modernidade não resta dúvida, desde que por este conceito não nos leve a contrabandeá-lo arbitrariamente para o horizonte da teoria crítica, que obviamente não tinha nada a ver com o seu. Sabemos que o marxismo realizou um grande esforço de confronto com Weber, diálogo que tem sérios opositores, como Herbert Marcuse (1965), mas também fortes defensores, como Georg Lukács (1968). Tal confronto será decisivo para toda evolução da assim chamada teoria crítica da Escola de Frankfurt (Wiegershaus, 1998), mas nem por isso o "marxismo ocidental" (Habermas, 1981) apresentou-se sob a rubrica de "marxismo weberiano" (Löwy, 2013) já que tinha plena consciência de que uma fusão entre Weber e Marx é, no final das contas, impossível. E o motivo fundamental não reside no campo da epistemologia, mas no plano normativo mesmo, já que o pensamento de Marx, na tradição de Hegel, busca a superação dos opostos, qual seja, a reconciliação [Versöhnung], enquanto Weber, filho da tradição kantiano-liberal, é um pensador do politeísmo de valores. No eixo do pensamento de Weber está a guerra dos deuses e não, como em Hegel, qualquer tipo de síntese entre os polos da totalidade (representada 
pela polis grega) e da individualidade (representada pela sociedade civil moderna), tema que ainda encontra eco em Marx e na tese da humanidade reconciliada com sua natureza essencial. Isso não exclui, é claro, que existam muitos pontos de contato entre as ontologias do presente que nos foram legadas por Marx e Weber, um elo que está longe de ser secundário.

Mas se a vertente do marxismo ocidental ainda tem plena consciência do fato de que sua incorporação de Weber é tópica e seletiva, isso não parece ser claro no já citado marxismo weberiano. Além da ênfase unilateral e descontextualizada em torno célebre passagem em que Weber (MWG I/9, p.422) emprega a expressão "Stahlhartes Gehäuse" - que Parsons, para o bem ou para o mal, traduziu como iron cage [Jaula de Ferro] - , Weber é arbitrariamente inserido na tradição da crítica romântica do capitalismo. Quanto a esse ponto, deveríamos notar que o dado que Weber realmente lamentava em sua época é que a ideia de dever profissional tenha perdido seu significado ético e "ronda pela nossa vida como um fantasma dos conteúdos religiosos do passado" (MWG I/9, p.422). O problema é que o dever profissional perdeu sua conexão com os valores culturais mais elevados e acabou reduzido à coação econômica. O protestante, ao tornar-se profissional, fez uma escolha. Realizou, portanto, um ato livre. O horizonte da crítica weberiana, fica claro, é o liberalismo.

No fundo, a sedutora imagem de um Weber trágico e resignado ou até mesmo um crítico romântico do capitalismo - duas interpretações que estão em afinidade eletiva - é muito mais o reflexo do espírito do nosso tempo [Zeitgeist] do que a tradução da visão pessoal e intelectual que ele mesmo tinha do mundo. Depois do fim das metanarrativas, conclusão quase obvia após um século de barbárie, um Weber niilista, trágico, desconsolado e melancólico, praticamente um fatalista (Weiss, 1987), teve um papel importante para que uma geração inteira de intelectuais se desse conta da ambivalência das utopias modernas que prometeram e redenção do mundo. Diante desse paradoxo das consequências não premeditadas (reflexo de um intelectualismo cosmo-ético que tem dificuldade de lidar realisticamente com a incongruência do mundo e que rapidamente desemboca em uma ética da convicção que não mede seus efeitos), Weber não alimentava nenhuma ilusão. Mas isso não o transforma na soma de pessimismo cultural com teoria crítica avant la lettre. É claro que Weber não é um pensador que celebra de modo triunfal e acrítico o progresso humano e ele tem plena consciência dos dilemas da contemporaneidade, mas se quisermos realmente mergulhar no espírito de sua obra temos que nos afastar dessas imagens e entender, definitivamente, que ele é um intelectual situado primordialmente na tradição da Aufklärung, e não da Romantik.

Em favor desse suposto Weber nietzschiano ou até kafkiano costuma-se invocar uma fala registrada pelo seu sobrinho Eduard Baumgarten (1964, p.554), segundo a qual ele teria dito que a correção de um intelectual contemporâneo pode ser medida por sua capacidade de posicionar-se diante de Karl Marx e 
Friedrich Nietzsche. Ora, demarcar sua posição em relação a esses dois gigantes do pensamento não significa, obviamente, segui-los. Assim como Weber não era nenhum discípulo de Karl Marx, tampouco o seria de Friedrich Nietzsche. O desafio consiste precisamente em traçar seu próprio caminho, tanto é assim que Weber tratou logo de explicar qual era a sua posição. E para ele precisamos nos manter equidistantes tanto do materialismo quanto do psicologismo, tanto da determinação econômica dos fenômenos sociais quanto da sua atribuição a fatores individuais, em particular ao ressentimento, com a "qual [uma ética religiosa] não tem nada a ver" (MWG I/19, p.9).

Assim como Weber não é nenhum criptomarxista, tampouco era um protonietzschiano, e apesar de todo esforço em aproximá-lo desse grande mestre da suspeita (como em Fleischmann, 1964), tal exercício nunca consegue ir muito além do paralelismo (Hennis, 1987), alimentando-se indefinidamente de falsos cognatos, já que não há como traçar um vínculo genético ou sistemático entre os dois pensadores (Schluchter, 1996). Aliás, se há um pensador ao qual realmente deveríamos remeter os fundamentos últimos do pensamento de Weber, esse não poderia ser outro que Immanuel Kant (Schluchter, 2005). Embora ele não defendesse nenhuma sociologização integral do kantismo (como vamos encontrar no Durkheim de As formas elementares da vida religiosa), trata-se de uma sociologia de orientação kantiana, e isso muito além do plano lógico-epistemológico. Sem Kant como pano de fundo não temos como entender a distinção entre as formas racionais de ação (ação racional de fins e ação racional de valores, racionalidade formal e material e racionalidade teórica e prática, ou seja, em última instância, razão pura e razão prática) e muito menos seu esforço em descrever esse verdadeiro imperativo categórico que é a moral puritana e sua valorização do trabalho como "dever", base de toda civilização ocidental-moderna. Quanto ao plano normativo, a distinção entre ética da convicção e ética da responsabilidade está inteiramente na direção da moral deontológica e não deve nada a uma suposta vontade de potência. É Kant de uma ponta a outra: epistemologia, método, teoria sociológica, teoria da modernidade, teoria da racionalização, teoria ética etc. $\mathrm{O}$ mesmo vale para sua sociologia da dominação, pois é fácil reconhecer na distinção kantiana entre o plano interior da moralidade e o plano coercitivo do direito a diferenciação entre legitimidade e aparato administrativo.

Portanto, longe de olhar passivamente a roda da fortuna, existe sim um projeto weberiano da modernidade, desde que esteja claro que ele não pertence ao mundo da utopia e não tem um caráter totalizante. Nesse ponto Jürgen Habermas (1981) tem inteira razão, e nós, concordando com ele, podemos afirmar que também para Weber "a modernidade é um projeto inacabado". Weber é o teórico da colisão de valores [Wertkonflit] e não um pensador da totalidade que julga encontrar na humanidade totalmente reconciliada [Versöhnung] com sua natureza original o ponto final da história. É realmente um exercício precário inseri-lo em uma forçada história de longo alcance da teoria da alienação e da 
reificação (Vandenberghe, 2012). A premissa de qualquer ação dentre do mundo consiste justamente em aceitar a realidade de uma modernidade desencantada que coloca por terra as imagens metafísicas do mundo, sejam elas religiosas, sejam seculares. Diante dessa dura realidade, "a transcendência da vida mística ou a fraternidade das relações diretas e recíprocas" (MWG I/17, p.109-110) não deixam de ser uma opção, mas só para aqueles que "não conseguem suportar virilmente o destino de nossa época". A esses é facultado voltar aos braços abertos e calorosos das velhas igrejas. No entanto, esses resignados têm sempre um preço a pagar: o sacrifício do intelecto. Weber não pertencia a esse grupo de resignados e a renúncia ao intelecto - o coração da Aufklärung - está fora de questão. Mas qual era, então, sua opção de vida?

\section{Para além da Realpolitik: crítica de Wolfgang Mommsen}

Se realmente desejamos responder a pergunta acima e acessar o núcleo normativo-ideológico do pensamento de Weber precisamos superar ainda mais um obstáculo. Ocorre que, depois do seminal trabalho de Wolfgang Mommsen sobre a teoria política de Weber (1974), caiu sobre ele a pesada acusação de um forte nacionalismo e de uma concepção meramente realista-instrumental de política (Realpolitik), leitura que ainda encontra forte eco no Brasil (Cohn, 2016, p.143-56; Mata, 2020). Logo Weber, o teórico cosmopolita par excellence (Roth, 2002)? A reação foi tamanha (especialmente por parte de Johanes Winckelmann (1952) e Karl Löwenstein (1961) que Mommsen (1974) não só apresentou uma edição revisada da obra, como, ao final, acabou por expressar-se em termos menos unilaterais, preferindo falar de um "liberalismo ambivalente" (Mommsen, 1982). No fundo dessa leitura reside a tese de que o pensamento político de Weber - em particular sua sociologia política - é completamente desprovido de fundamentos normativos. Eis aqui o problema central que nos cabe analisar. De fato, na tipologia weberiana, a dominação carismática e tradicional apelam para conteúdos concretos de legitimidade (a missão e a tradição), enquanto a dominação racional-legal aparenta assentar-se em critérios estritamente formais. Com base nessa leitura alegou-se que, como não havia lugar para fundamentos extralegais no ordenamento jurídico moderno, a posição weberiana antecipava a posição positivista de Hans Kelsen. Weber foi posto, assim, no fulcro de uma pergunta vital: qual a legitimidade da legalidade (Legitimität kraft Legalität)? Com base nesse questionamento, o autor passou a ser criticado por todos os lados do espectro ideológico.

No campo conservador, Leo Strauss (1953) e Eric Voegelin (1995) lamentavam a falta de ausência de fundamentos jusnaturalitas em sua obra, enquanto Carl Schmidt (1932) procurava extrair daí o que julgava ser sua consequência mais importante: por trás da ordem jurídica formal esconde-se em verdade a decisão política, verdade que nos é revelada no estado de exceção. Os campos liberal e marxista, apesar de suas diferenças, compartilhavam do mesmo diagnóstico crítico. Para o materialismo histórico, na prática Weber teria ancorado sua 


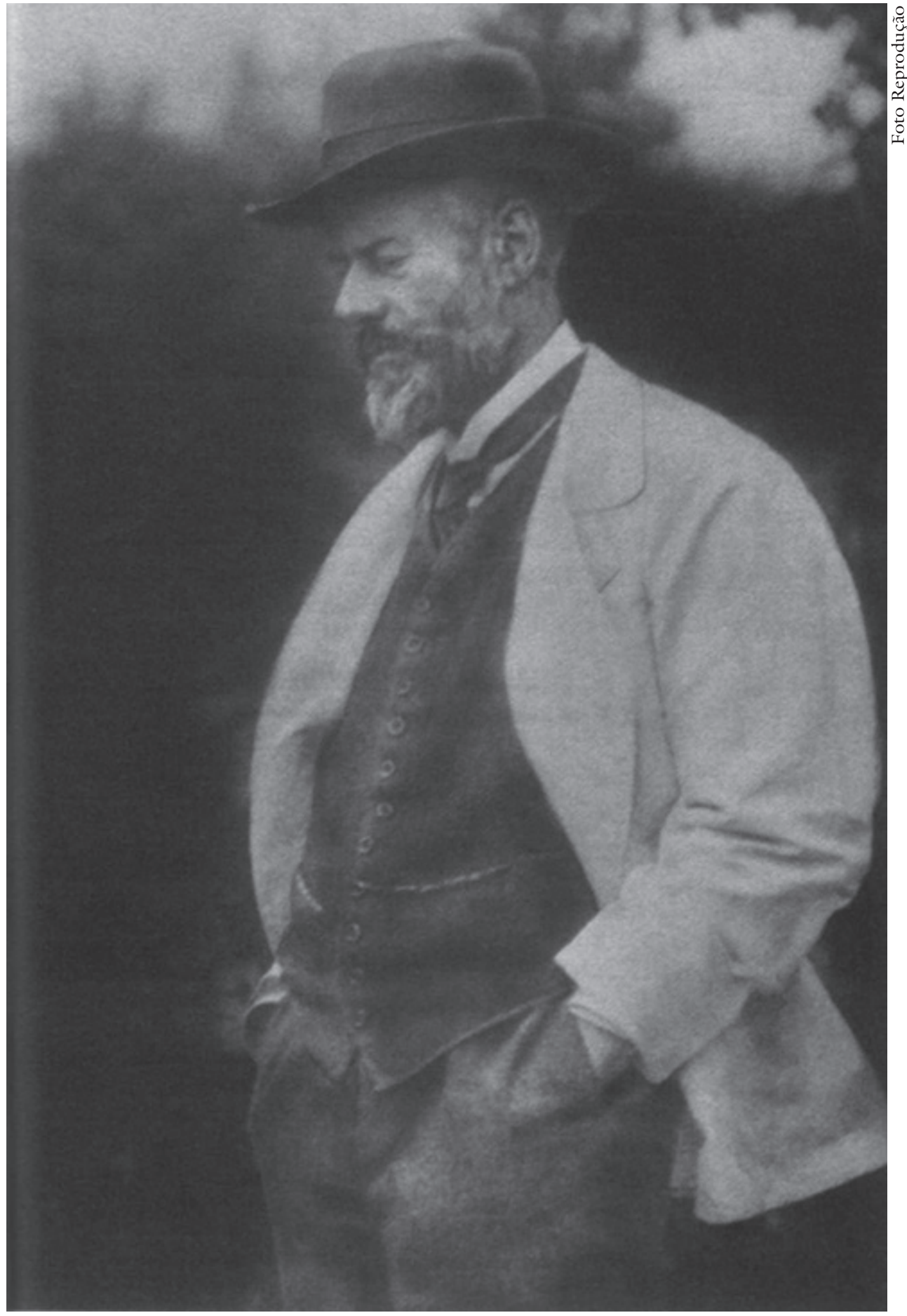

Max Wilhelm Carl Weber (1864-1920). 
visão política no decisionismo (Habermas, 1973) e no irracionalismo (Lukács, 1954; Marcuse, 1965), enquanto os autores liberais acusavam-no de ter recaído no realismo político (Mayer, 1985), ou mesmo em um nacionalismo de corte imperialista (Mommsen, 1974).

A literatura anglo-saxã, talvez porque menos comprometida com a trágica história alemã, foi mais equilibrada e trabalhos como os de David Beetham (1974), Richard Bellamy (1994), Anthony Giddens (1988), entre outros, voltaram a colocar o pensamento weberiano em suas bases liberais. Quanto aos tons nacionalistas de Weber, Kari Palonen $(1999 ; 2001)$ vem mostrando, com os melhores métodos histórico-conceituais oriundos da escola linguística, o quanto a semântica do jovem Weber transita do nacionalismo (caso de $O$ Estado nacional e a política econômica, de 1895) para uma decidida opção pelo vocabulário da liberdade. É por desconsiderar essa evolução cronológica que a maioria dos estudos se equivoca, aí incluído o célebre trabalho de Mommsen.

$\mathrm{Na}$ esteira de Mommsen, a questão da legitimidade das instituições políticas foi palco de um importante debate entre a teoria da ação comunicativa e a teoria dos sistemas, cabendo a Luhmann a defesa da prioridade do princípio da legalidade e a Habermas a defesa do princípio da legitimidade. Dessa diferença resulta que enquanto Luhmann (1969, p.27-38) interpreta o conceito weberiano de legitimação como uma teoria consensual e afirma que ela demanda a aceitação da legalidade enquanto crença coletivamente compartilhada, Habermas (1973, p.133-40) defende a posição exatamente contrária e sustenta que a definição weberiana elimina essa diferença. Conclusão: para Luhmann, Weber sobrepõe a legitimidade à legalidade, enquanto para Habermas ele suprime a legitimidade em favor da legalidade (Lübbe, 1991).

Diante de tamanho desacordo, só nos resta perguntar: qual era a posição de Weber? Tal pergunta nos leva inevitavelmente aos textos do próprio autor. Sob esse ângulo, o problema precisa ser reformulado em outros parâmetros, desembocando na seguinte questão: qual a relação que Weber estabelece entre seus quatro tipos de ação e seus três tipos de dominação? Por que o número de tipos de dominação não coincide com a tipologia da ação? Diante dessa nova indagação surgiram duas respostas.

Para Wolfgang Mommsen (1974), os três tipos puros de dominação têm uma exata correspondência com um tipo específico de ação social, nos seguintes termos: a dominação carismática seria a tradução da ação social afetiva, a dominação tradicional seria a correspondente da ação social tradicional, restando tão somente correlacionar dominação legal com ação racional com relação a fins. Em função dessa leitura, Mommsen conclui que a teoria weberiana da ordem legal moderna contém, em seu núcleo, um déficit normativo, pois não resta dúvida de que ela está desconectada de valores: seu substrato é totalmente formalista.

Essa interpretação foi desafiada por Johannes Winckelmann (1952), para quem o conjunto da dominação não deve ser vinculado, caso a caso, com cada 
um dos tipos de ação, mas apenas com uma variante do agir, da qual ela é uma extensão: a ação racional com relação a valores. Essa é a razão pela qual Weber não tinha nenhuma necessidade de elaborar quatro tipos de domínio em correspondência exata com os mesmos modos de agir. Consequentemente, o vínculo entre o ordenamento jurídico-político e seu caráter normativo, cuja fonte é a ação racional com relação a valores, jamais é quebrado. Aliás, que no âmbito político existe um vínculo intrínseco entre essas duas esferas está indiscutivelmente claro a partir da distinção que, já na versão antiga de Economia e sociedade, Weber estabelece entre a "dominação em virtude de uma constelação de interesses" (própria da esfera do mercado) e a "dominação em virtude da legitimidade" (própria da esfera da política). Portanto, não é preciso vincular necessariamente legitimidade com ação racional com relação a valores para que o caráter normativo da legalidade esteja devidamente fundamentado (Schluchter, 1988).

\section{Liberalismo multidimensional}

Interpretações de tipo criptomarxista acabam por contrabandear Weber para um horizonte ideológico que não era o seu. Já as visões protonietzschianas ou formalistas deixam a porta aberta para entendê-lo como nacionalista ou decisionista, pois na ausência de fundamentos normativos resta como única via de orientação da política a razão de Estado. Mas, se tais leituras nos conduzem para caminhos equivocados, resta que nossa pergunta fundamental ainda está sem resposta: qual era, afinal, a concepção ideológica de Weber?

\section{A condução ética da vida}

Ela é, em primeiro lugar, um projeto de condução ética, cujo ponto nodal é o conceito de "personalidade". Aqui Weber deita raízes em um elemento profundo da cultura alemã: a noção de Bildung. A noção, como sabemos, remonta a Wolfgang Goethe e ao estilo literário do Bildunsgroman, sintetizado em seu magistral Anos de aprendizado de Wilhelm Meister, início de uma longa tradição que passa por Thomas Mann (com o jovem Hans Castorp em A montanha mágica), o Demian de Herman Hesse, entre outros. Mas, é com Hans Georg Gadamer (1999) que a noção de Bildung ganha, por assim dizer, sua melhor expressão filosófica. Gadamer explica que a Bildung não deriva etimologicamente do termo forma [Form], mas da palavra "imagem" [Bild] com suas variantes Nachbild e Vorbild [modelo]. Mais do que desenvolver aptidões preexistentes, a Bildung implica um processo de interiorização da exterioridade, qual seja, um processo histórico de apropriação subjetiva da cultura pensada não como meio, mas como fim em si mesmo. Seu norte é o desenvolvimento da personalidade.

Não por acaso, alguns dos textos mais reflexivos do autor, momentos em que ele se permitia expressar em termos dos seus próprios valores, terminam com referências a Johann Wolfgang Goehte. Em Politica como profissão, por exemplo, ele dirá: "é preciso entregar-se ao trabalho e responder às exigências do dia, seja humanamente, seja profissionalmente" (MWG I/17, p.23). O tema 
já é antigo e podemos encontrar as mesmas ressonâncias literárias nos escritos de A ética protestante e o "espírito" do capitalismo, escrito no qual ele explica claramente que:

[...] a limitação a um trabalho especializado e a consequente abdicação a faustiana universidade humana constituem, no mundo de hoje, uma condição sine qua non da atividade válida. Isto é, "ação" e "renúncia" são hoje em dia interdependentes. Esta motivação radicalmente ascética do estilo de vida burguês - supondo que seja estilo, e não ausência de estilo - foi o que na sua sabedoria nos quis mostrar Goethe na sua obra Wanderjahare e no fim que deu a seu Fasto. (MWG I/9, p.421)

A essência do conceito de personalidade "reside na coerência entre a conduta interior e determinados valores ou significados últimos da existência" (Weber, 1988 , p.132). Como explica Schluchter $(2012$, p.55) "esse conceito de personalidade corresponde a um individualismo ascético-humanista: ascético, porque se trata de agir em conformidade com uma causa impessoal; humanista porque essa causa deve estar amparada em valores últimos; individualista, porque essa referência a valores últimos supõe a possibilidade de escolha".

Esse individualismo ascético-humanista exclui a possibilidade de colocar Weber ao lado de uma concepção romântico-dionisíaca da vida, como muitos (Lallement, 2013), atualmente, sentem-se tentados a fazê-lo, principalmente aqueles que exploram os detalhes das suas relações íntimas. Para aqueles que "buscam sensações românticas" (MWG I/17, p.250) ou mesmo aqueles que estão à cata do re-encantamento da vida pelo amor (Pierucci, 1999) -, Weber tinha um recado muito claro: "limitação a um trabalho especializado" e "entrega às exigências do dia". Nem a arte, muito menos o erótico - duas formas diferentes de busca da redenção ${ }^{1}$ - mas a ascese intramundana, ou em termos atuais, uma condução ético-reflexiva da existência, de caráter humanista, individualista e ascético, era esse o projeto de vida que Max Weber escolheu. Foi o que ele procurou transmitir aos estudantes quando convidado a proferir duas conferências sobre os requisitos necessários para a profissão de cientista ou para o exercício da política como atividade profissional: no lugar do éros, o ethos.

\section{A luta pela liberdade}

As opções valorativas de Weber não se encerram no plano ético-pessoal, dado que esse individualismo ascético-humanista requer determinadas condições socioinstitucionais para que seja exequível. No plano político a possibilidade de uma condução autônoma da existência traduz-se como liberalismo. Que era essa a opção política de Weber, não resta qualquer dúvida, bastando para tanto consultar um documento como Parlamento e Governo na Alemanha reordenada no qual, entre tantas tarefas imediatas, ele menciona a importância da "preservação da liberdade e do individualismo" e as "possibilidades da democracia" (MWG I/15, p.465-466). Essa não era uma tarefa a menosprezar, pois se diante do socialismo a unificação da burocracia estatal com a econômica 
nos prepara a morada da servidão do futuro, nem por isso devemos achar que está dada inexoravelmente a combinação entre capitalismo e liberdade, como argumenta ele em suas belas análises sobre a transição da Rússia ao pseudoconstitucionalismo. As “árvores do individualismo democrático não crescem até o céu" e "chega a ser cômico atribuir ao capitalismo avançado, tal como ele existe na América e vem sendo importado para a Rússia, uma afinidade eletiva com a "democracia" ou até mesmo com a "liberdade" (MWG I/15, p.270). O que Weber renega é a velha ideia de "tendências de desenvolvimento" chamando a atenção para o fato de que o surgimento da moderna liberdade, combinada com a democracia e com o capitalismo, supõe uma constelação de condições que não se repete simplesmente como uma lei imanente. A liberdade só é possível com a ação "decidida e permanente da vontade de uma nação" (MWG I/16, p.270). A liberdade não é fruto da necessidade histórica, mas da vontade humana, e isso sempre dentro de condições socioculturais que podem favorecê-la ou obstruí-la.

Contudo, se a opção de Weber pela liberdade como horizonte valorativo é clara, quando se trata de determinar o conteúdo e natureza do liberalismo por ele professado, as dificuldades são bem maiores. No Brasil esse tema rendeu um interessante debate, com interpretações radicalmente distintas, pois enquanto o marxista Maurício Tragtenberg (1992), na linha de Mommsen, ainda viu em Weber o representante do "liberalismo possível”, o liberal José Guilherme Merquior (1991), na linha de Ernest Gellner, entendeu que se tratava de um "semiliberalismo". Curiosa contradição.

No plano coletivo ainda não dispomos de uma expressão síntese que capture sua concepção do liberalismo de modo global, como no caso do plano ético. Também porque não se trata de um sistema doutrinário do qual tudo pode ser deduzido, pois não podemos esquecer que, do ponto de vista teórico, o que Weber elaborou foi uma sociologia política, não uma filosofia política erigida em sistema. Assim, difícil reduzir tudo a expressões únicas como liberalismo ético, democrático, social, constitucional, burocrático-democrático, voluntarista, ou mesmo a determinado conceito de liberdade (Palonen, 2001), ainda que cada uma dessas expressões nos revele algum aspecto importante. Por essa razão, talvez o melhor caminho para atingir seu núcleo ainda é o da história social, o que nos permite resgatá-lo em seus nuances, sem pretender uma totalização arbitrária. Isso também nos permite compreender que a posição política de Weber se desenha em resposta a problemas e desafios oriundos da conjuntura de seu tempo.

Se nos reportamos ao âmbito biográfico-contextual, não há dúvida de que temos que situar Weber no seu milieux social-cultural próprio: a burguesia liberal-protestante (Hübinger, 2016). Apesar das diferentes organizações científicas e políticas da qual ele fez parte - Congressos Sociais Evangélicos, Associação para a Politica Social, Arquivo para a Politica Social, Sociedade Alemã de Sociologia, Partido Nacional-Liberal e Partido Democrático Alemão, é nesse meio que ele 
forma suas convicções e estabelece suas redes sociopolíticas. Dentre as figuras mais importantes para entender sua cosmovisão política devemos contar, sem dúvida, Friedrich Naumann. ${ }^{2}$ Este político, junto com Max Weber, Hugo Preuss, Theodor Heuss, Alfred Weber, Lujo Brentano e outros está na fonte do chamado "liberalismo nacional-social", uma fórmula que diz muito sobre seu universo político. Mas, o que quer dizer essa expressão que reúne, aparentemente, elementos tão desconexos? Como podemos combinar o "liberal", somado ao "nacional" e ao "social"?

\section{Liberalismo social}

No plano da "política social" Weber defende uma posição muito peculiar (MWG I/8). Ele recusa tanto as soluções existentes à esquerda quanto à direita. Do campo da esquerda, ele se distancia por criticar igualmente o socialismo estatal e o patriarcalismo estatal de Otto von Bismarck. Por outro lado, ele também não adere ao liberalismo do laisser-faire. Esses últimos reduzem a política social à política econômica e querem desestatizá-la enquanto àqueles primeiros reduzem tudo a ação do Estado. Weber e seu grupo defendem a auto-organização da sociedade, opção que podemos denominar de "política social liberal" e que não por acaso fez com que eles fossem chamados de "socialistas de cátedra". A chave dessa concepção social-liberal não está nem no egoísmo e nem no protecionismo estatal, mas no conceito de "voluntarismo". Do ponto de vista prático, isso levou Weber a defender enfaticamente a liberdade das organizações de representação de interesses, sejam elas ligadas a uma burguesia consciente de seu papel político, sejam os sindicatos enquanto defensores das demandas dos trabalhadores: seu objetivo era o reforço da sociedade civil.

Contudo, com a morte de vários de seus fundadores, inclusive do próprio Weber e de Naumann, o Partido Popular Alemão não vingou e foi sobrepujado, neste mesmo campo ideológico, pelo partido rival de Gustav Stresemann - o Partido Popular Alemão. Um eco longínquo e algo modificado dessa concepção, com maior acento no aspecto econômico, pode ser encontrado apenas nos pós-Segunda Guerra, com a fundação do Partido Democrático da Liberdade [FDP], em especial na ala identificada com o chamado ordo-liberalismo e sua defesa de uma economia social de mercado. Ralf Dahrendorf, um dos intelectuais públicos mais influentes dessa geração, é outro que preserva muitos desses impulsos weberianos (Hübinger, 2016).

\section{Liberalismo político-institucional}

A assim chamada "questão social" não exclui a "questão nacional", mas se existe um nacionalismo em Weber, ele não pode ser entendido como a defesa de um Estado fundado na homogeneidade cultural e no imperialismo expansionista, conforme as tintas exageradas de Mommsen. Tendo como horizonte uma ordem internacional composta por Estados em competição, o que ele defendia era apenas clareza das lideranças políticas quanto a necessidade de defender os interesses nacionais. A Alemanha era um Machtstaat e sua política externa tinha 
que levar esse fato em consideração. Mas isso diz respeito às relações internacionais. Mais problemática era a situação interna, pois nesse caso Weber constatava um descompasso entre um avançado processo de industrialização e um sistema político-institucional defasado que, entre outros arcaísmos, ainda mantinha regras eleitorais censitárias e a exclusão do voto feminino. Segundo o veredicto de Weber, um pseudoconstitucionalismo. Diante dessa conjuntura, a política institucional defendida por ele sempre foi a progressiva parlamentarização e democratização do sistema político. Quem se der ao trabalho de ler os principais escritos técnico-políticos weberianos constatará que o eixo de suas intervenções sempre foi a crítica da burocracia estatal e o reforço do papel do parlamento. Machtslosparlament [parlamento sem poder]: eis o constante lamento de Weber. Mesmo sua ênfase na necessidade de seleção de lideranças, é bom recordar, diz respeito sempre às lideranças político-parlamentares.

Ocorre que com a queda da monarquia e a instauração da república esse quadro mudou, forçando Weber a alterar certos elementos de seu "desenho institucional". No entanto, a tão discutida proposta de democracia plebiscitária (Sell, 2011), via eleições diretas para presidente, não deve ser concebida de forma unilateral, como se fosse a única medida sugerida por ele. $\mathrm{O}$ formato institucional defendido por Weber está atravessado por um sistema de pesos e contrapesos. Ao lado da eficiência da "burocracia" precisamos contar com um "parlamento" responsável, alimentado por lideranças políticas treinadas em "partidos políticos" de massa; sistema, por sua vez, legitimado por ampla participação eleitoral, aí incluída a eleição direta do mandatário da nação. Uma "sociedade civil" composta por organizações capazes de representar e disputar seus interesses completa esse quadro (Kim, 2004). E não por último, a demarcação de tarefas entre o mercado-capitalista e o Estado Legal-Burocrático também deveria ser mantida, evitando que ambas as burocracias, uma vez fundidas, resultassem em uma sociedade petrificada.

\section{Conclusão}

Após termos indagado pelas opções de Weber no plano ético e coletivo - e este segundo na sua dupla dimensão "social e político-institucional" - podemos nos perguntar ainda se elas também se deixam caracterizar no plano da representação de mundo, quer dizer, no plano das orientações de valor [ Wertorientierung]. Dessa forma inserimos a concepção política weberiana em seu esquema sociológico de análise, que contempla os planos micro, macro e simbólico (ação, ordem e cultura). Também aqui temos que nos precaver de reducionismos fáceis, pois se há uma expressão que Weber preza é o politeísmo de valores. E, mais uma vez, temos que nos manter atentos aos falsos cognatos, pois não se trata da Grécia pré-socrática de Nietzsche, mas da heterogeneidade das esferas de valor da tradição neokantiana. Peter Lassman (2004), de modo apurado, salientou que essa ideia representa bem mais do que mero pluralismo, pois é da colisão de valores que se trata. É esse o preço a pagar pelo desencantamento 
do mundo, pois "as diferentes ordens de valor encontram-se em permanente luta" (MWG I/17, p.99). Trata-se de uma verdadeira guerra "como nos velhos tempos que ainda não eram desencantados dos seus deuses e demônios, ainda que com outro sentido: pois assim como Helena fazia oferendas para Afrodite, e então para Apolo e sobretudo para os deuses da cidade, assim ainda é nosso comportamento hoje, embora de modo desencantado e sem o revestimento mítico, mas internamente com a mesma verdade plástica" (MWG I/17, p.100).

A pluralidade do mundo, acompanhada das suas tensões inerentes, é um valor que Weber deseja preservar. No plano da ação, ela requer um indivíduo livre e autônomo, que precisa fazer escolhas éticas e ser coerente com elas. Ao mesmo tempo, no plano das organizações sociais, a autonomia deixa liberdade para a articulação múltipla e a expressão pública das demandas e interesses sociais. Por fim, no plano político-institucional, ela requer uma ordem de pesos e contrapesos mediante a qual as diferentes instituições exercem, umas sobre as outras, uma vigilância constante. E isso na melhor tradição liberal da separação e equilíbrio de poderes, tanto nas instâncias políticas quanto na configuração das esferas sociais do mercado e do Estado. É por buscar fundar as possibilidades da liberdade através dessa síntese complexa, que não exclui tensões, equilibrando os planos individual e coletivo e, especialmente, os planos social e político-institucional, que podemos localizar Weber, em fórmula que nos remete ao presente, no centro democrático-progressista: democrático na sua face política, e progressista na sua face social. Era esse o caminho que, filiando-se ao DDP de Friedrich Naumann, Weber procurava defender para a nascente República de Weimar. E sem esquecer do mais importante: a opção pela liberdade, seja no plano cultural, seja no plano institucional, seja ainda no plano individual, requer sempre a luta. Na feliz expressão de Gangolf Hübinger (2019), longe de um liberalismo consensual [Konsensliberalismus], Weber professa um Konfliktliberalismus, qual seja, um liberalismo do conflito, fórmula que também poderíamos apresentar, em alusão ao debate contemporâneo, como liberalismo agonístico.

\section{Notas}

l A arte como "salvação intramundana do cotidiano e das pressões do racionalismo prático e ético" (MWG I/19, p.501) e o erótico como sublimação da sexualidade cultivada de forma consciente e extracotidiana" (MWG I/19, p.503) são discutidos por Weber em sua Consideração Intermediária (MWG I/19, p.501).

2 Uma ampla discussão sobre a relação pessoal e intelectual de Weber com personalidades políticas de sua época (como Friedrich Nauann, Walther Rathenau, Gustav Stresemann, Dietrich Schäffer, e outros) pode ser encontrada na coletânea organizada por Momm$\operatorname{sen}(1988)$.

\section{Referências}

BAUMgarTen, E. Max Weber: Werk und Person. Tübingen: Mohr Siebeck, 1964. 
BELLAMY, R. Liberalismo e sociedade moderna. São Paulo: Editora Unesp, 1994.

BEETHAM, D. Max Weber and the Theory of Modern Politics. London: George Allen \& Unwid, 1974.

COHN, G. Critica e resignação. São Paulo: Martins Fontes, 2003.

. Soberania e responsabilidade: Weber sobre Parlamento e Governo. In: Weber,

Frankfurt: teoria e pensamento social 1. Rio de Janeiro: Azougue, 2016. p.143-58.

FLEISCHMANN, E. De Weber à Nietzsche. European Journal of Sociology. Archives Européennes de Sociologie. Europäisches Archiv Für Soziologie, v.5, n.2, p.190-238, 1964.

GADAMER, H. G. Verdade e método: traços fundamentais de uma hermenêutica filosófica. 3.ed. Petrópolis: Vozes, 1999.

GIDDENS, A. Politica, sociologia e teoria social. São Paulo: Unesp, 1988.

HABERMAS, J. Legitimationsproblem im Spätkapitalismus. Frankfurt a.M.: Suhrkamp, 1973.

. Theorie des kommunikativen Handelns. Zur Kritik der funktionalistischen Vernunft. Frankfurt a.M.: Suhrkamp, 1981.

HENNIS, W. Max Webers Fragestellung. Studien zur Biographie des Werks. Tübingen: Mohr Siebeck, 1987.

HÜBINGER, G. Engagierte Beobachter der Moderne. Von Max Weber bis Ralf Dahrendorf. Düsseldorf: Wallstein, 2016.

. Max Weber: Stationen und Impulse einer intellektuellen Biographie. Tübingen: Mohr Siebeck, 2019.

KIM, S. H. Max Weber's Politics of Civil Society. Cambridge: Cambridge University Press, 2004.

LALLEMENT, M. Tensions majeures. Max Weber, l'économie, l'érotisme. Paris: Gallimard, 2013.

LASSMAN, P. Political Theory in an Age of Disenchantment: The Problem of Value Pluralism: Weber, Berlin, Rawls. Max Weber Studies, v.4, n.2, p.251-69, 2004.

LEPSIUS, M. R. Demokratie in Deutschland. Tübingen: Vandenhoeck \& Ruprecht, 1993.

LÖWEINSTEIN, K. Max Weber als “Ahnherr” des plebiszitären Führerstaats. Kölner Zeitschrift für Soziologie und Sozialpsychologie, v.13-2, p.274-89, 1961.

LÖWY, M. A jaula de aço: Max Weber e o marxismo weberiano. São Paulo: Boitempo, 2013.

LÜBBE, W. Legitimität kraft Legalität: Sinnverstehen und Institutionenanalyse bei Max Weber und seinen Kritikern. Tübingen: Mohr Siebeck, 1991.

LUHMANN, N. Legitimation durch Verfahren. Frankfurt a.M.: Suhrkamp, 1969.

Geschichte und Klassenbewusstsein. Berlin: Hermann Lichterland, 1968. v.2, p.161-518.

MARCUSE, H. Industrialisierung und Kapitalismus. In: STAMMER, O. (Org.) Max Weber und die Soziologie heute: Verhandlungen des 15. Deutschen Soziologentages in Heidelberg 1964. Tübingen: Mohr Siebeck, 1965. p.161-80. 
MATA, S. da. Morto há cem anos, Weber ensina que radicalismo é falência da política. Folha de S.Paulo, Ilustríssima, 4 de julho de 2020.

MAYER, J. P. Max Weber e a política alemã. Brasília: Editora da UnB, 1985.

MERQUIOR, J. G. O Liberalismo: antigo e moderno. Rio de Janeiro: Nova Fronteira, 1991.

MOMMSEN, W. J. Max Weber und die deutsche Politik 1890-1920. 2.ed. Tübingen: Mohr Siebeck, 1974.

. Max Weber. Gesellschaft, Politik und Geschichte. Frankfurt: Suhrkamp, 1982.

MOMMSEN, W. J.; SCHWEINKTER, W. (Org.) Max Weber und seine Zeitgenossen. Göttingen: Vandenhoeck \& Ruprecht, 1988. p.682-702.

PALONEN, K. Max Webers Reconceptualization of Freedom. Political Theory, v.27, p.523-544, 1999.

. Was Max Weber a 'Nationalist'. A Study in the Rhetoric of Conceptual Chan-

ge. Max Weber Studies, v.1, p.196-213, 2001.

PIERUCCI, A. F. O sexo como salvação neste mundo. In: VIII JORNADAS SOBRE ALTERNATIVAS RELIGIOSAS NA AMÉRICA LATINA, 1999, São Paulo. O futuro da religiosidade latino-americana. São Paulo, Centro Universitário Maria Antônia/USP, 1999. p.42.

ROTH, G. Max Weber: family history, economic policy, exchange reform. Soc. estado., Brasília, v.17, n.1, p.64-78, June 2002.

SCHLUCHTER, W. Die Entstehung des modernen Rationalismus: Eine Analyse von Max Webers Entwicklungsgeschichte des Okzidents. Frankfurt a.M: Suhrkamp, 1988.

Zeitgemässe Unzeitgemässe. Von Friedrich Nietzsche über Georg Himmel zu Max Weber. In: Unversöhnte Moderne. Frankfurt am.M: Suhrkamp, 1996. p.144-65.

Werturteilsfreiheit und Wertdiskussion: Max Weber zwischen Immanuel Kant und Heinrich Sickert. In: Handlung, Ordnung und Kultur. Tübingen: Mohr Siebeck, 2005. p.86-107.

Max Weber acerca da ciência e da política como vocações. In: $\mathrm{Pa}-$

radoxo da modernidade: cultura e conduta na teoria de Max Weber. São Paulo, Editora Unesp, 2012.

SCHMIDT, C. Legalität und Legitimität. München: Duncker \& Humblot, 1932.

SELL, C. E. Democracia com liderança: Max Weber e o conceito de democracia plebiscitária. Rev. Bras. Ciênc. Polit., Brasília, n.5, p.139-66, July 2011.

. Max Weber e a racionalização da vida. Petrópolis: Vozes, 2013.

STRAUSS, L. Natural Right and History. Chicago; London: The University of Chicago Press, 1953.

TRAGTENBERG, M. Burocracia e ideologia. 2.ed. São Paulo: Ática, 1992.

VANDENBERGUE, F. Uma história filosófica da sociologia alemã. Alienação e reificação. Rio de Janeiro: Annablume, 2012.

VOEGELIN, E. Die Grosse Max Webers. München: Fink, 1995. 
WEBER, M. Asketischer Protestantismus und Kapitalismus. Schriften und Reden 19041911. Org. Wolfgang Schluchter e Ursula Bube. Tübingen: Mohr Siebeck, 2014. (MWG, I/9)

WEBER, M. Zur Russischen Revolution von 1905. Schriften und Reden 1905-1912. Org. Wolfgang J. Mommsen e Dittmar Dahlmann. Tübingen: Mohr Siebeck, 1989. (MWG I/10).

Zur Politik im Weltkrieg. Schriften und Reden 1914-1918. Org. Wolfgang J. Mommsen e Gangolf Hübinger. Tübingen: Mohr Siebeck, 1984. (MWGI/15)

. Zur Neuordnung Deutschlands. Schriften und Reden 1918-1920. Org. Wol-

fgang J. Mommsen e Wolfgang Schwentker. Tübingen: Mohr Siebeck, 1988. (MWG $\mathrm{I} / 16)$

Wissenschaft als Beruf 1917/1919 / Politik als Beruf 1919. Org. Wolfgang J. Mommsen, Wolfgang Schluchter e Birgitt Morgenbrod. Tübingen: Mohr Siebeck, 1992. (MWG I/17)

WEISS, J. On the Irreversibility of Western Rationalization and Max Weber's Alleged Fatalism. In: LASH, S.; WHIMSTER, S. Max Weber, rationality and modernity. London: Allen \& Unwin, 1987. p.154-63.

WIGGERSHAUS, R. Die Frankfurter Schule. Geschichte, Theoretische Entwicklung, Politische Bedeutung. DTV, München 1988.

WINCKELMANN J. Legitimität und Legalität in Max Webers Herrschaftssoziologie. Tübingen: Mohr Siebeck, 1952.

RESUMO - Qual o liberalismo de Weber? Após a crítica de algumas das interpretações vigente no Brasil, argumenta-se que o liberalismo ético-agonístico de Weber é de natureza multidimensional e desdobra-se tanto no plano existencial quanto no plano coletivo do social e do político. Partindo do fato de que a cultura moderna é marcada pelo pluralismo e pelo conflito de valores, Weber apregoa um liberalismo social que defende a livre-organização dos grupos sociais e um liberalismo politico-institucional no qual Estado e capitalismo, por um lado, e o conjunto das instituições políticas, por outro, operam em tensão permanente, bem como atuam como um sistema de pesos e contrapesos que visa manter aberto o espaço da luta pela liberdade.

PALAVRAS-CHAVE: Max Weber, Liberalismo, Liberalismo social, Democracia, Pluralismo, Conflito.

ABSTRACT - Of what type is Weber's liberalism? After criticizing some of the current interpretations in Brazil, it is argued that Weber's ethical-agonistic liberalism is multi-dimensional and unfolds both on the existential and on the collective level of social and political reality. Starting from the fact that modern culture is marked by pluralism and the conflict of values, Weber advocates a social liberalism that defends the free organization of social groups and a political-institutional liberalism in which the State and capitalism, on the one hand, and the set of political institutions, on the other hand, operate under permanent tension, the latter also acting as a system of checks and balances that aims to keep open the space for the struggles for freedom.

KErWords: Max Weber, Liberalism, Social liberalism, Democracy, Pluralism, Conflict. 
Carlos Eduardo Sell é doutor em Sociologia Política e professor do Programa de PósGraduação em Sociologia Política da Universidade Federal de Santa Catarina (UFSC). Realizou pós-doutoramento na Universidade de Heidelberg. @ - carlos.sell@ufsc.br / https://orcid.org/0000-0002-3281-7045.

Recebido em 10.9.2020 e aceito em 27.9.2020.

I Programa de Pós-Graduação em Sociologia Política, Universidade Federal de Santa Catarina, Florianópolis, Santa Catarina, Brasil. 